\title{
Physical Modeling Study on Combined Side and Top Blowing AOD Refining Process of Stainless Steel: Back-attack Phenomenon of Gas Streams with Horizontal Side Blowing and Its Influence on Erosion and Wear of Refractory Lining
}

\author{
Ji-He WEI, ${ }^{1)}$ Hong-Li ZHU, ${ }^{1)}$ Qing-Yuan JIANG, ${ }^{2 l}$ Guo-Min SHI, ${ }^{1,2)} \mathrm{He}-\mathrm{Bing} \mathrm{CHI}^{2)}$ and Hai-Jiang WANG ${ }^{1)}$ \\ 1) Department of Metallic Materials, College of Materials Science and Engineering, Shanghai University, Shanghai, 200072, $P$. \\ R. China. E-mail: jihew@staff.shu.edu.cn $\quad$ 2) Stainless Steel Branch, Baoshan Iron \& Steel Co., Ltd., Shanghai, 200431, \\ P. R. China.
}

(Received on January 4, 2010; accepted on June 24, 2010)

\begin{abstract}
The back-attack phenomenon of the gas side blowing streams and its influence on the erosion and wear of the refractory lining during the combined side and top blowing AOD refining process of stainless steel were investigated on a water model unit of a $120 \mathrm{t}$ AOD converter. Sufficiently full kinetic similarity between the model and its prototype was maintained. The influences of the gas flow rates for side and top blowing, the side tuyere position and number were examined. The preliminary industrial experiments were conducted. The results indicated that the presence of a gas top blowing jet and using of multiple tuyeres did not change the basic features of the back-attack, but could give it some distinctive behaviors. The back-attack could indeed bring about the evident and uneven erosion and wear of the lining. On the back-attack, the gas streams of the main tuyeres had a decisive role, and the subtuyere streams showed a certain suppression and alleviation effect. At a given tuyere number and position, its frequency and pressure and the total average pulse number in per unit time in the processes of this work increased with an increase in the gas side blowing rate. At a given tuyere position and gas side blowing rate, the back-attack and its influence on the erosion and wear of the lining enhanced with decreasing the tuyere number (increasing the gas flow rate for single tuyere). The gas top blowing jet could make the back-attack become more uniform and its frequency decrease, and its intensity and the total average pulse number increase; and it could reduce the eroded and worn rate of the lining at a given tuyere number and position and gas side blowing rate. The increased amplitude of the back-attack intensity and the extension of the damaged area of the lining caused by the buoyancy in a combined blowing were smaller and lower than those in a simple side blowing. As another important reason resulted in the back-attack and the erosion and wear of the lining, the effectiveness of the circulatory motion of the liquid in a combined blowing is different from that in a simple side blowing. At a given tuyere number, properly increasing the angle between each tuyere could be beneficial to alleviating the back-attack and to slowing down the erosion and wear of the lining. Under the conditions of this work, the back-attack actions and the lining eroded and worn extents and rates with 7 tuyeres and $22.5^{\circ}$ or 6 tuyeres and $27^{\circ}$ were all gentler and lower than those with the other tuyere equipments and arrangements. The results obtained from the physical modeling studies on the refining process were reliable, believable and valid. Suitably increasing the angle between each tuyere of the $120 \mathrm{t}$ AOD converter could raise the life of its lining by a big margin, and remarkably improve the technical and economic indications of the process.
\end{abstract}

KEY WORDS: stainless steel; AOD refining; combined side and top blowing; horizontal gas stream; back-attack phenomenon; erosion and wear of refractory lining; physical modeling.

\section{Introduction}

During the AOD (argon-oxygen decarburization) refining process, the refractory lining near the tuyere outlets can be excessively and non-uniformly eroded and worn, resulting in its short working life. This is the most serious shortcoming of the process, and the back-attacking of the horizontal gas streams would be a very important reason to cause this kind of situation like that. In order to prolong its lining life, a lot of efforts have been made in the past decades after this process was bone, and great advances have been achieved. However, raising the lining life has still been an important and crucial subject for studying of AOD refining technology of stainless steel.

As regards the back-attack phenomena of the gas streams, in fact, they unavoidably take place in all the metallurgical processes with the submerged gas blowing and injecting. Many studies ${ }^{1-14)}$ had been performed under dif- 
ferent blowing conditions for the purpose of alleviating or suppressing and eliminating them, but a complete picture for them could not be gotten. Wei et al. ${ }^{15)}$ have made a review for those. Also, taken an $18 \mathrm{t}$ AOD vessel with two side tuyeres as a prototype, they investigated better and more reliably the phenomena of the horizontal blowing rotating and non-rotating gas streams by use of water modeling. Their results have made people get a better and deeper knowledge and understanding about those. For the back-attack phenomenon of horizontal gas streams in a combined side and top blowing, there is not any report in the literature, except a preliminary investigation. ${ }^{16)}$

Moreover, the studies by Wei et al. ${ }^{15,16)}$ verified that the non-uniform erosion and wear of the AOD lining is closely concerned with the gas blowing condition and fluid flowing pattern in the bath, particularly the back-attacking of the gas side blowing streams. At the prerequisite of keeping the sufficiently full kinematic similarity between the model and its prototype, water modeling has been utilized to investigate the gas stirring and fluid flow and mixing in the bath of a $120 \mathrm{t}$ AOD converter with the combined side and top blowing, and some good results have been attained. ${ }^{17,18)}$ On the basis of those, a water modeling study on the back-attack of the horizontal gas streams with its influence on the erosion and wear of the lining during the blowing process of stainless steel has then been carried out. And the preliminary industrial experiments have been done. The related results are reported in this paper.

\section{Experimental Methods and Conditions}

Figure 1 is the schematic diagram of the model unit of the $120 \mathrm{t}$ AOD converter employed for water modeling experiments with a geometric similarity ratio of $1: 4$, in which (a) and (b) are for the back-attack of the horizontal gas streams and the erosion and wear of the lining, respectively. Except the systems for measurement, it was completely the same as that given in Refs. 17) and 18). The back-attack frequency and intensity of a horizontal gas stream were uninterruptedly monitored and detected by means of an antiwater pressure sensor made especially; its dimensions were $\phi_{\text {in }} 10 \times \phi_{\text {out }} 14 \times 10 \mathrm{~mm}$. The site for measuring the back-attack pressure was located at the over zone just close to the outlet of the middle tuyere (see Fig. 1(a)). In that case, the lower edge of the sensor was in contact with the tuyere outlet end, and its back surface was closely fixed to the inner side wall of the model vessel with the daub, and its front surface was kept in a same perpendicular plane with the outlet section of the tuyere. In addition, the output signals were measured and digitally displayed by a dynamic resistance strain-meter of YD-21 model. Simultaneously, the back-attack (pressure) waves were recorded with a lightbeam oscilloscope of SC-16A model.

For the erosion and wear experiments of the lining, the boric acid plate utilized for modeling the lining was made from the boric acid powder with analytical purity by means of melting and casting. Its dimensions were $120 \times 120 \times 15$ $\mathrm{mm}$. At the time of the experiment, the back surface and all sides of the weighed plate were daubed with the daub to isolate them from the water. Then, it was closely put and kept on the outlet end of the middle tuyere, and fixed on the inclined sidewall of the model (see Fig. 1(b)). When the specified values of the gas blowing rates of the main tuyeres and subtuyeres and/or top lance were reached and maintained to be stable, the time began to be numbered. The gas blowing treatment time was $30 \mathrm{~min}$. While the treatment was over, all the water in the vessel was discharged, the sample plate was taken out, and reweighed after it was dried. Moreover, the photograph of the eroded and worn surface was also taken to record its morphology and appearance. The dissolved and eroded amount of the plate in the periods of pouring and discharging the water before and after the treatment was determined from the preliminary experiment. Drawn the lessons gotten in the preliminary investigation, ${ }^{16)}$ some improved measures were adopted, thus being sure to conduct smoothly the experiment and also raising the accuracy and reliability of the experimental data.

The back-attack behaviors and features of the gas side blowing streams were observed under the different blowing conditions. The corresponding back-attack frequencies and pressures were measured. The influences of the gas side and top blowing rates, the tuyere number and the angle between each tuyere were examined. The operating modes used were the same as those used in the studies of the gas stirring and fluid flow and mixing in the bath, shown in Table $\mathbf{1}^{17,18)}$ In this Table, 7 tuyeres $/ 18^{\circ}$ and the gas top
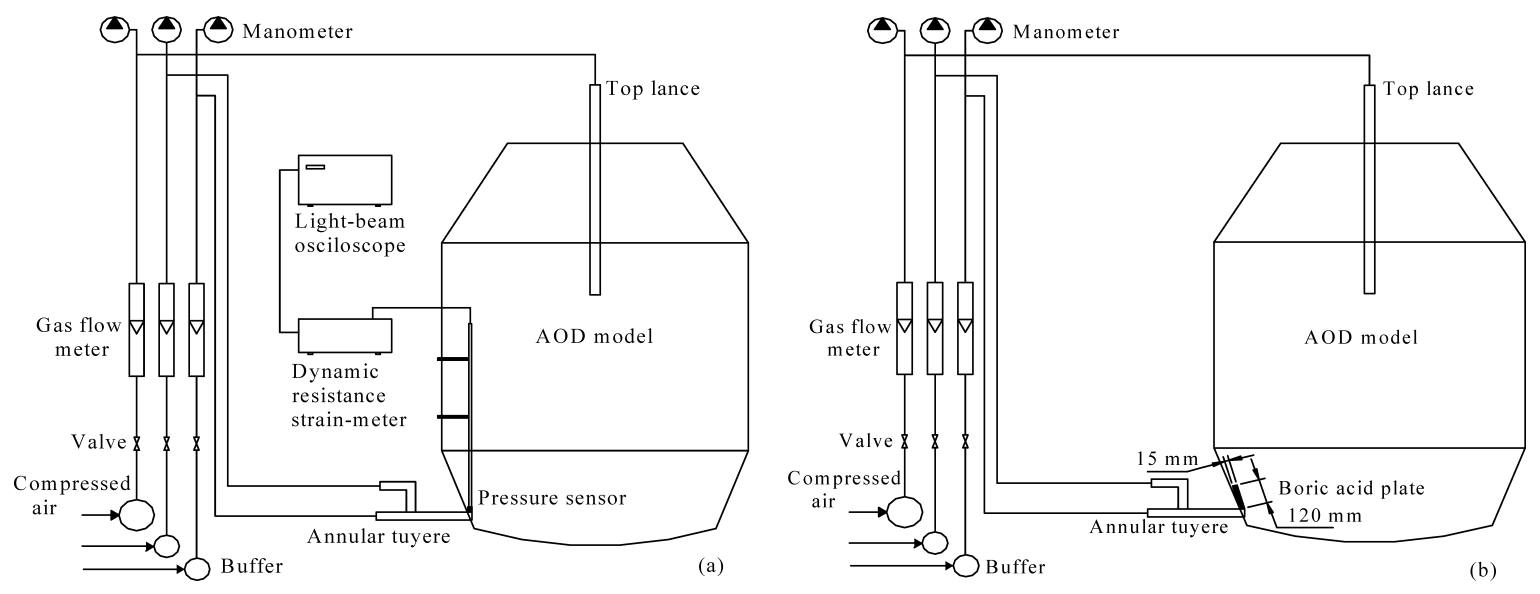

Fig. 1. Schematic diagram of the water model apparatus of the $120 \mathrm{t}$ AOD converter utilized for water modeling experiments: (a) for back-attack of gas side blowing streams; (b) for erosion and wear of refractory lining. 
Table 1. All operating modes used for water modeling experiments on back-attack of gas side streams in the present work.

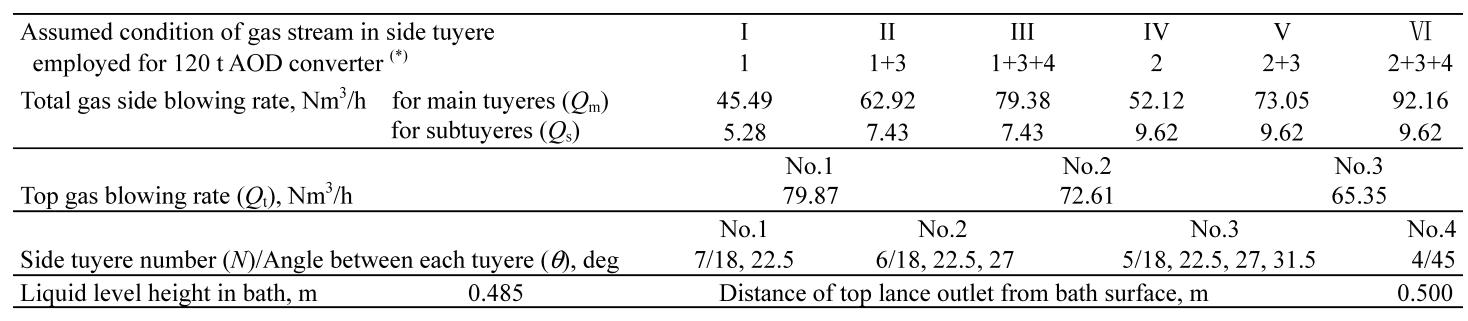

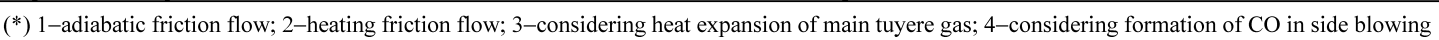

blowing rate of $79.87 \mathrm{Nm}^{3} / \mathrm{h}$ were corresponding to the tuyere equipment and arrangement and the oxygen gas flow rate of $6600 \mathrm{Nm}^{3} / \mathrm{h}$ in the existing practice, separately.

For the erosion and wear experiments of the lining, besides that of 7 tuyeres with $18^{\circ}$ used for the prototype, the other seven kinds of tuyere equipments and arrangements, i.e. 7 tuyeres with $22.5^{\circ}, 6$ tuyeres with $22.5^{\circ}$ and $27^{\circ}, 5$ tuyeres with $22.5^{\circ}, 27^{\circ}$ and $31.5^{\circ}$, and 4 tuyeres with $45^{\circ}$, were chosen and taken in this work. The gas blowing rates of the main tuyeres, subtuyeres and top lance all were $92.16,9.62$ and $79.87 \mathrm{Nm}^{3} / \mathrm{h}$, respectively. It may be presumed that at these gas blowing rates, the gas stirring and liquid flow pattern in the water model bath would probably be closer to those in the prototype bath during the refining process. ${ }^{17)}$

\section{Experimental Results and Discussion}

\subsection{Back-attack Phenomenon of Horizontal Gas Streams}

During the gas blowing and injecting experiments, the evident back-attack phenomenon of the gas side blowing streams was visualized. Under the conditions of the simple side blowing, the gas blown horizontally through multiple tuyeres entered into the bath in the form of multiple streams. These streams were curvedly moving upward after penetrating a certain distance along the axes of the tuyeres in the bath liquid. During changing of the motion direction into the upward from the horizontal, they collapsed and a few of large bubbles were formed at the not too far locations from the tuyere outlets. These bubbles separated from the bulks of the streams were moving backward and impinging against the side wall over the tuyere outlets under the oppression of the liquid in motion with the buoyancy, and broken into the small bubbles. Then, the small bubbles produced in this way were floating and ascending upward along the side wall following after the liquid. At the same time of the large bubbles detaching, the whole streams were contracting toward the outlet directions of the tuyeres, attacking on the front surfaces of the outlets and the side wall around them, thus generating one back-attack. Then, the streams were extending forward by driving of the succeeding following-up gas, and carrying within themselves the next back-attack. This process was repeatedly carrying on like that. The larger the gas flow rate, the fewer the tuyere used, the longer the distance became. Relevantly, the generated position of the large bubble was gradually away from the tuyere outlet, and its size was gradually decreasing. These features had all been observed during the water modeling of the blowing process in an $18 \mathrm{t}$ AOD vessel. ${ }^{15)}$ How- ever, there were some different aspects between the both. The large bubbles formed were much smaller than those in the model bath of an $18 \mathrm{t}$ AOD vessel due to increasing of the capacity and tuyere number. Moreover, there were the much stronger interactions among the gas streams after entered into the bath. Particularly, the two streams of the most outside could strongly be attracted by the others included between them, thus evidently deviating towards the middle.

During a combined blowing process, the top blowing gas jet can impede the gas discharge in the tuyeres and the ascending motion of the gas-liquid two-phase flow formed by the horizontal gas streams. Also, it can intensify the upward (at the outlet side of the tuyeres) and downward (at the side opposite the tuyere outlets) motion of the bath liquid along the wall resulted from the horizontal gas streams, ${ }^{17)}$ thus influencing the back-attack. The visualizations and the experimental results showed that the jet did not alter the basic characteristics of the back-attack, but could make its action become more uniform and its frequency and intensity (pressure) change.

As pointed out by Wei et al. ${ }^{15)}$ the back-attacking of a horizontal gas stream, in a broad sense, should include three parts. One is the simple (narrow sense) back-attack action of the residual bulk of the stream at the tuyere outlet $^{9-12)}$; the second is the counteraction of the stream ${ }^{6}$; and the third is the striking of the bubbles separated from the stream bulk against the side wall under the repression of moving liquid. In the case of a combined blowing, the impinging of a gas top blowing jet should also be considered. Also, the phenomenon is closely related with the circulatory motion of the bath liquid. Moreover, the buoyancy can give an important influence. It can not only enhance the backward-contracting attack force and the thrust force suffered by the bubbles, but also change the motion direction of the bubbles. The effects of a top blowing gas jet and the buoyancy will further be analyzed and discussed later.

\subsection{Back-attack Frequency of Horizontal Gas Streams}

The changes in the back-attack frequency with the total gas side blowing rate during the AOD water modeling of simple side and combined blowing at different operating modes are presented in Figs. 2 and 3(a), respectively. Under the conditions of this work, the frequencies were in the range of 9 to $17 \mathrm{~Hz}$ for the simple side blowing, and 8 to $11 \mathrm{~Hz}$ for the combined blowing in the case of using 7 tuyeres with $18^{\circ}$. It can be seen that at a given tuyere position and number, the frequencies all increased with an increase in the gas flow rate from the main tuyeres. However, compared to that during the water modeling of the gas blowing in an $18 \mathrm{t}$ AOD vessel, ${ }^{15)}$ the increased amplitudes were 


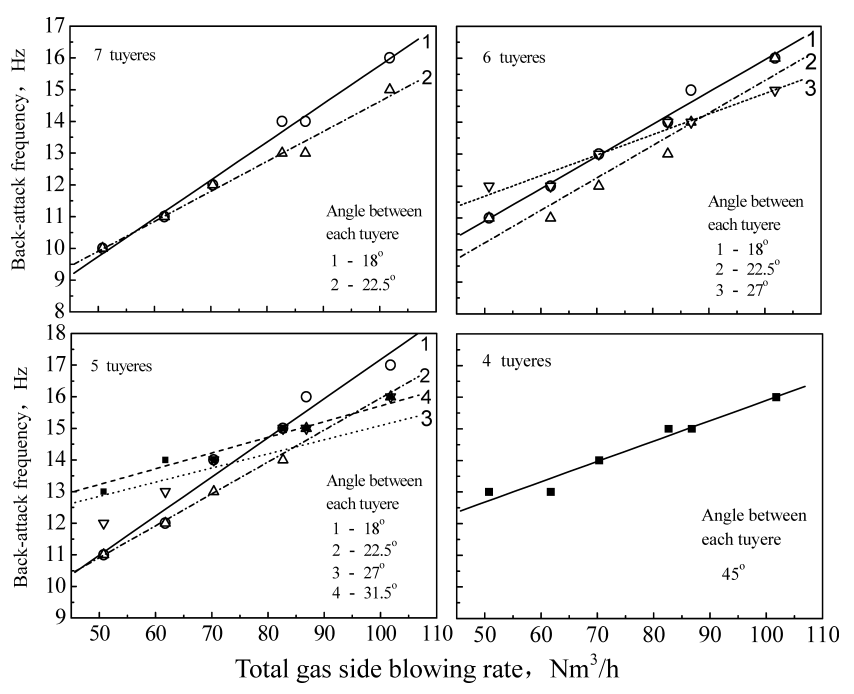

Fig. 2. Changes in back-attack frequency of horizontal gas streams with total gas side blowing rate during the AOD water modeling of simple side blowing at different tuyere numbers and positions.
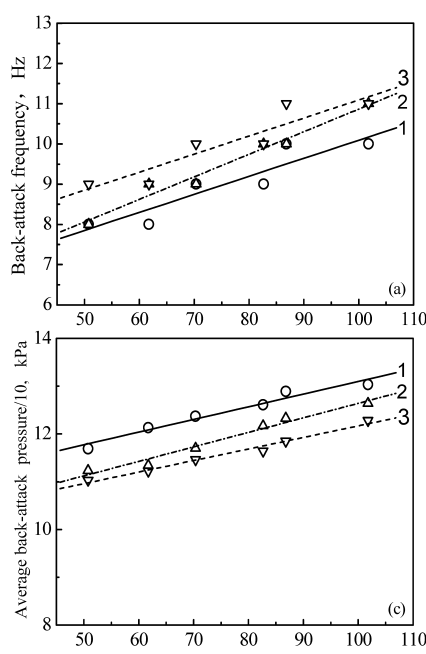

Total gas side blowing rate, $\mathrm{Nm}^{3} / \mathrm{h}$

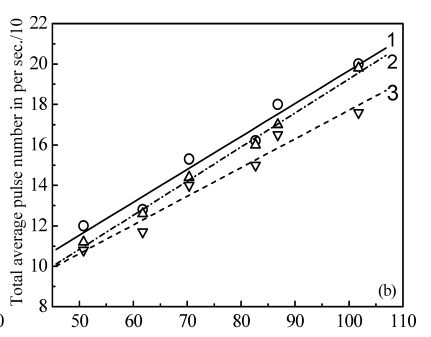

Total gas side blowing rate, $\mathrm{Nm}^{3} / \mathrm{h}$

7 tuyeres, $18^{\circ}$

Combined side and top

Blowing; Gas top blowing rate, $\mathrm{Nm}^{3} / \mathrm{h}$

$$
\begin{aligned}
& 1-79.87 \\
& 2-71.61 \\
& 3-65.35
\end{aligned}
$$

Fig. 3. Changes in back-attack frequency (a), total average pulse number in per second (b) and average back-attack pressure (c) of horizontal gas streams with total gas side blowing rate during the AOD water modeling of combined side and top blowing at a given tuyere number of 7 with an angle of $18^{\circ}$ between each tuyere and different gas top blowing rates.

smaller. It also appears that the blowing pressures used in the present work are all lower than the critical value, over that the frequencies would change into reducing. On the other hand, in the case of blowing through multiple tuyeres, the gas blowing rate for single tuyere would greatly decrease, and the gas blowing pressure would relevantly lower. As shown in Fig. 2, at a given tuyere position and total gas side blowing rate, the frequency with 5 tuyeres was a little higher than that with 7 or 6 tuyeres. Furthermore, under the conditions of this work, the influence of the angle between each tuyere on the frequency was not as obvious as that on the mixing time.

Figure 3(a) also demonstrated that a gas jet from the top lance could make the frequency decrease. This kind of the influence of the gas jet is understandable. Its impinging force (with a downward direction) can reduce the role of the buoyancy (with an upward direction), retard the progress of changing in the motion direction of the gas streams into the upward from the horizontal and slow down their collapsing, thus making the back-attack of them become more uniform and the frequency decrease.

The results obtained also showed that the gas stream of the main tuyere played a decisive role on the back-attack. However, under the conditions of gas blowing through multiple tuyeres, the subtuyere stream had also a shielding effect on it, and could suppress and alleviate it to a certain extent. This kind of effect is strengthened with increasing its relative gas flow rate to that from the main tuyere. It would be favorable to protecting the lining and prolonging its life.

During the back-attacking with multiple tuyeres and combined blowing, there would also be the multiple action points when the large bubbles and a group of the small bubbles impinging against the side wall. Each back-attack will all contain the striking actions of a group of the bubbles including the residual bulk of the stream. Those would be the same as that in the water modeling of the blowing process in an $18 \mathrm{t}$ AOD vessel. ${ }^{15}$ ) A small part of the back-attack waves obtained experimentally at the given blowing conditions is shown in Figs. 4-6. Obviously, there was a relevant group of positive and negative pulses for each back-attack. The pulse numbers involved in each back-attack were approximately similar to each other at a given operating mode, but being different from each other at different operating modes. Also, the total average pulse numbers corresponding to the back-attack frequencies during the simple side and combined blowing at the given operating modes are given in Figs. 7 and 3(b), respectively. It can be seen that at a given tuyere number and position, the mean pulse number in each back-attack and the total average pulse number in per unit time increased with increasing of the side and top blowing rates. Compared to those in the simple side blowing, the total average pulse numbers for the combined blowing respectively at the three gas flow rates of top blowing were all larger, although the frequencies were lower. At a given gas side blowing rate, the larger the gas top blowing rate, the larger the raised amplitude became. The impact of the gas jet can delay the collapse of the gas streams, but, can also accelerate breaking of the larger bubbles once they formed and produce still more small bubbles, thus resulting in increasing of the total average pulse number. At a given gas top blowing rate and tuyere number and position, the mean pulse number in each back-attack and the total average pulse number increased with a rise in the gas side blowing rate. These are in agreement with the influence of a top blowing gas jet on the back-attack behaviors mentioned above.

Figure 7 also illustrated that although the influence of the angle between each tuyere on the frequency was not so evident, at a given tuyere number and larger gas side blowing rate, the total average pulse number remarkably decreased with an increase of the angle in the range of $18^{\circ}$ to $27^{\circ}$. This suggested that at a given tuyere number and gas side blowing rate, properly increasing the angle would be advantageous to alleviating the back-attack. Relatively, the total average pulse number with 7 tuyeres and $22.5^{\circ}$ or 6 tuyeres and $27^{\circ}$ was the smallest. Also, at a given tuyere position 

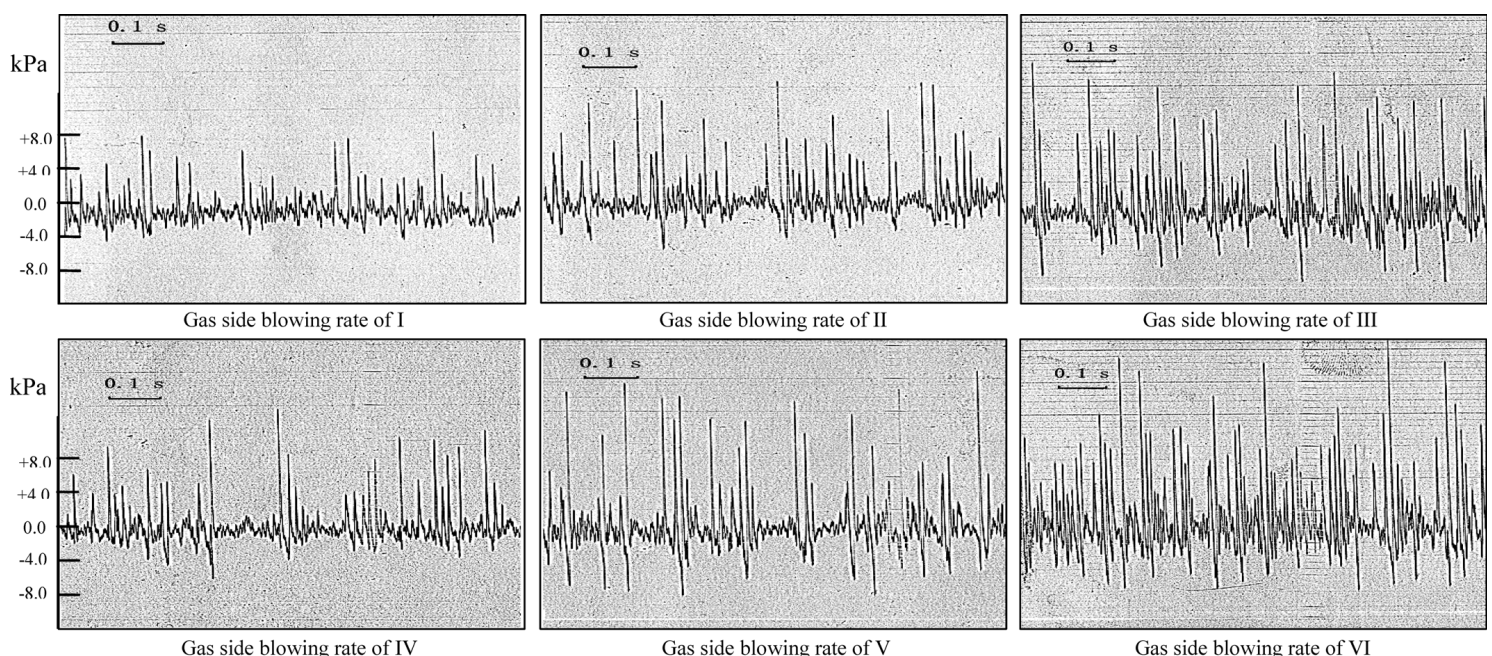

Fig. 4. Back-attack waves of horizontal gas streams during the AOD water modeling of simple side blowing with different gas blowing rates at a given tuyere number of 7 with an angle of $18^{\circ}$ between each tuyere.
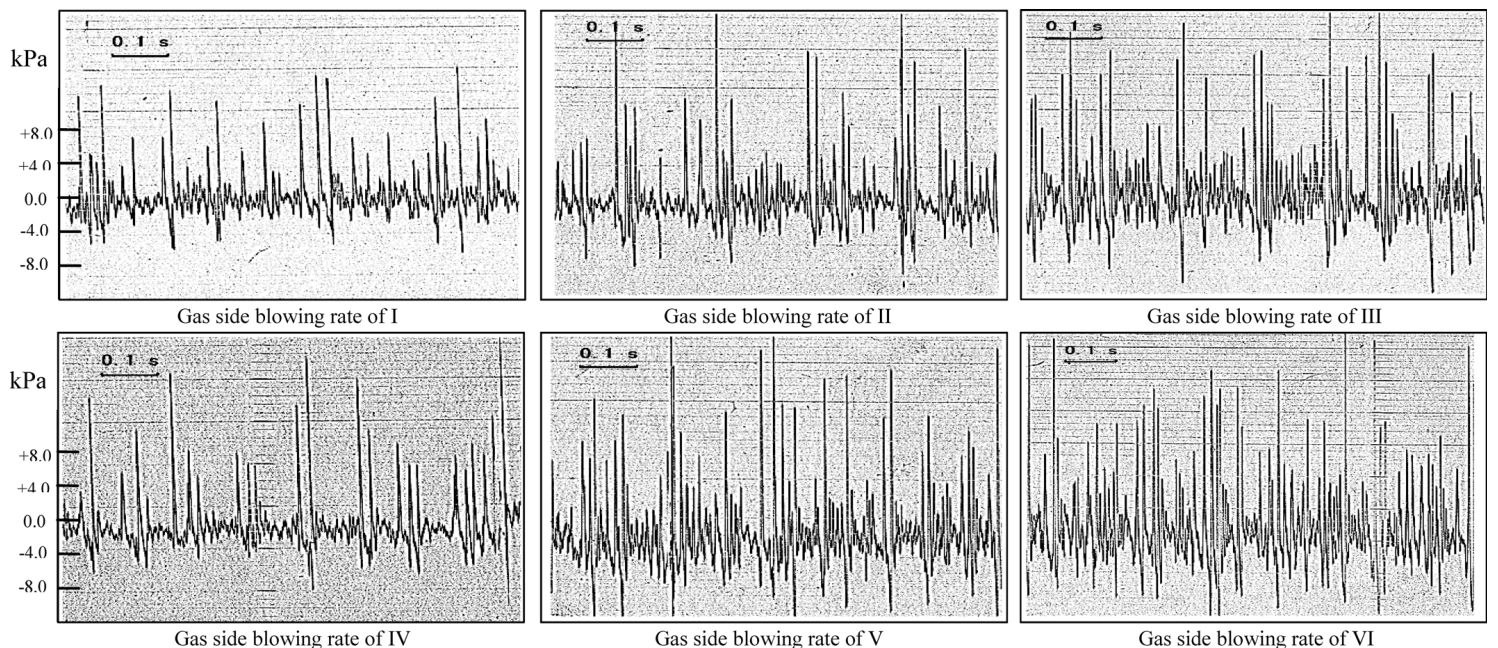

Fig. 5. Back-attack waves of horizontal gas streams during the AOD water modeling of simple side blowing with different gas blowing rates at a given tuyere number of 6 with an angle of $27^{\circ}$ between each tuyere.
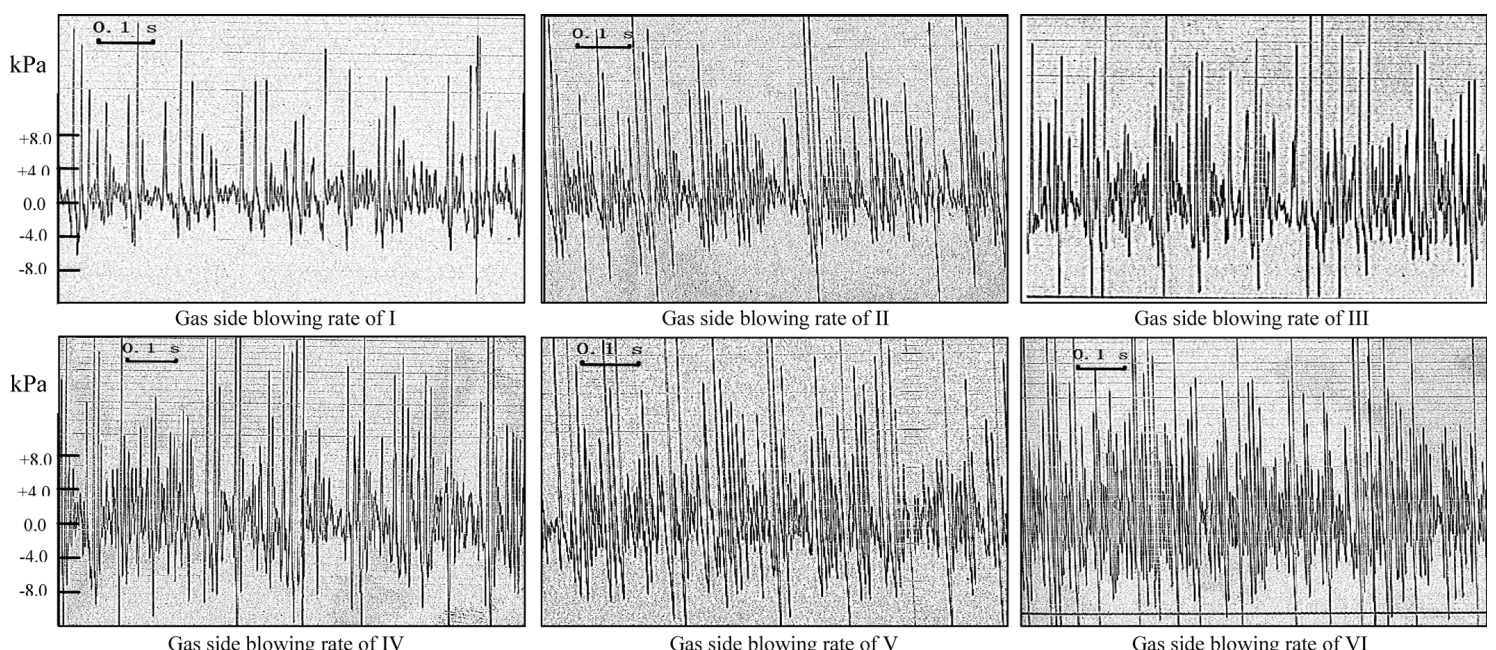

Fig. 6. Back-attack waves of horizontal gas streams during the AOD water modeling of combined side and top blowing with different side gas blowing rates at a given tuyere number of 7 with an angle of $18^{\circ}$ between each tuyere and gas top blowing rate of $79.87 \mathrm{Nm}^{3} / \mathrm{h}$. 


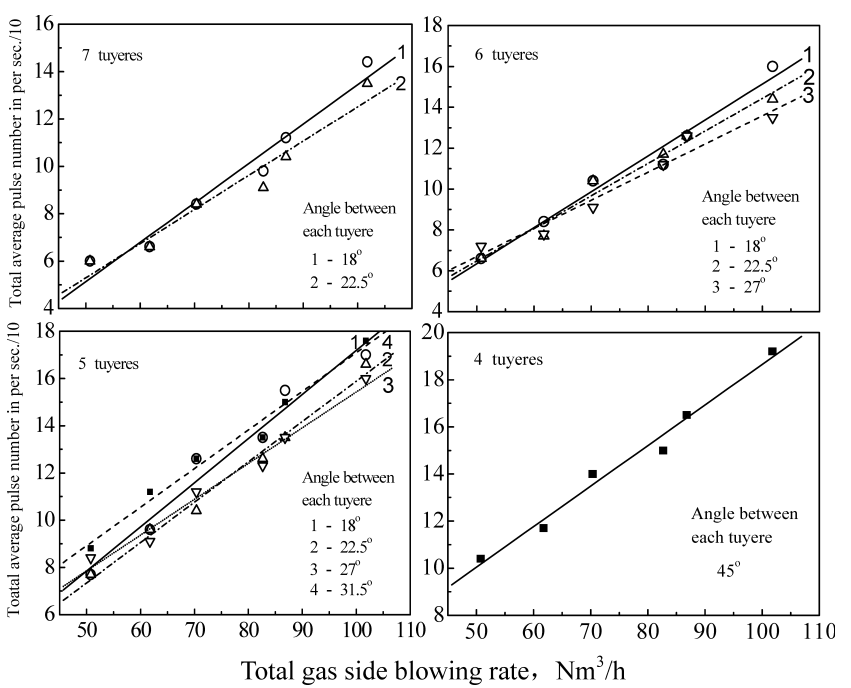

Fig. 7. Changes in total average pulse number (corresponding to the back-attack frequency of gas streams) with total gas side blowing rate during the AOD water modeling of simple side blowing at different tuyere numbers and positions.

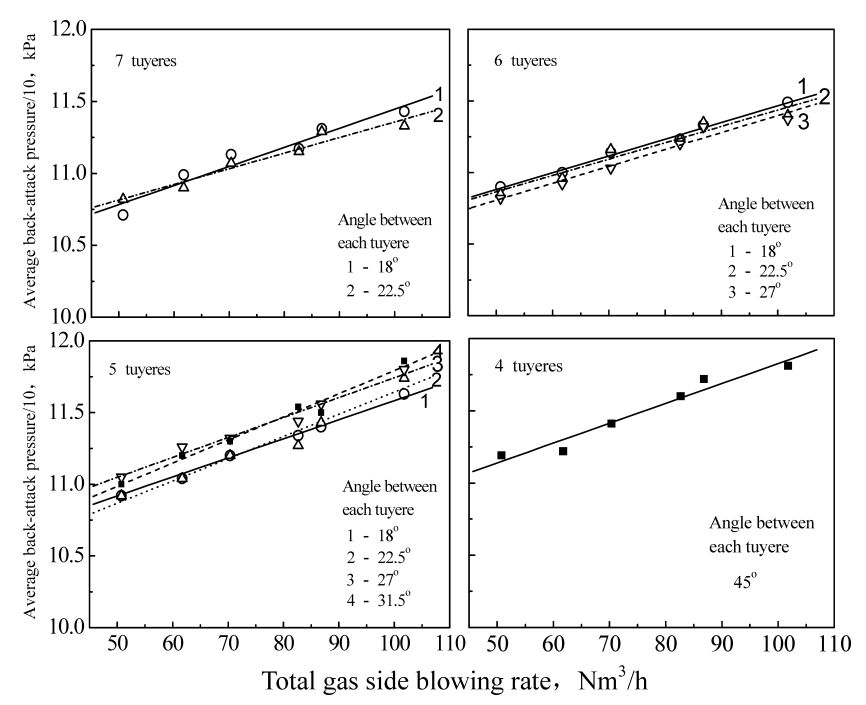

Fig. 8. Changes in average back-attack pressure of horizontal gas streams with total gas side blowing rate during the AOD water modeling of simple side blowing at different tuyere numbers and positions.

and gas side blowing rate, the total average pulse number increased with decreasing the tuyere number (increasing gas flow rate for single tuyere). These conform roughly to those obtained in the preliminary investigation. ${ }^{16}$ ) In one sense, the total pulse number would be able to reflect better the characteristics of the back-attack than the frequency.

\subsection{Back-attack Pressure of Horizontal Gas Streams}

Figures 8 and 3(c) give the average back-attack pressures of the horizontal gas streams at the different operating modes. All the value given here for the simple side blowing would be the sum of the three action forces mentioned above. As shown in Fig. 8, in the case of this work, the pressures for the simple side blowing were about 107.06 to $118.56 \mathrm{kPa}$, enhanced by 2.11 to $13.61 \mathrm{kPa}$ than the static pressure borne by the gas streams at the tuyere outlets. The appropriate maximal pressures were about 112.54 to $139.18 \mathrm{kPa}$, lowered by 15 to $30 \%$ than the values of the water modeling of the blowing process in an $18 \mathrm{t}$ AOD vessel. ${ }^{15)}$ On the whole, at a given tuyere number and position, the larger the gas side blowing rate, the higher the pressure was. At a given tuyere position and gas side blowing rate, it decreased with increasing the tuyere number. At a given tuyere number and gas side blowing rate, it somewhat reduced with enlarging the angle between each tuyere in the range of $18^{\circ}$ to $27^{\circ}$, like that for the average total pulse number.

This kind of changing pattern of the back-attack pressure is able to be understood. At a given tuyere number and position, the larger the gas side blowing rate, the higher the gas blowing pressure is. At a given tuyere position and gas side blowing rate, the fewer the tuyere used, the larger the gas flow rate for single tuyere is. At a given tuyere number and gas side blowing rate, the smaller the angle between each tuyere, the stronger the interactions among the gas streams are. All of these can all enhance the pressure. Similar to that for the total average pulse number, the pressures relevant to using 7 tuyeres and $22.5^{\circ}$ or 6 tuyeres and $27^{\circ}$ at the given gas side blowing rates were in a smallest range.

For the combined blowing, the back-attack pressure determined experimentally would also include impinging of the gas jet, besides the three actions described before. The impinging must be able to enhance the back-attack intensity to some extent. Under the conditions of this work, the average back-attack pressures in the combined blowing with 7 tuyeres and $18^{\circ}$ were about 110 to $130 \mathrm{kPa}$ (see Fig. 3(c)). Compared to the values in the relevant simple side blowing, those were higher by 3 to $16 \mathrm{kPa}$. These are roughly equivalent to the estimated impinging forces of the jets at the appropriate flow rates. ${ }^{19)}$ Due to the limit from the measurement range of the resistance strain-meter, the back-attack waves obtained in the combined blowing were not complete. Thus, it was difficult to get the maximal pressures. The general pattern was that the jet raised the back-attack intensity. This is corresponding to the liquid flow pattern in the bath and the behaviors and back-attack features of the gas streams in the combined blowing. However, because of the variation of liquid turbulence in a combined blowing, the forces acted on the pressure sensor and detected by it would not necessarily direct all to the side wall. This is one of the discrepancies of the back-attack phenomena of the horizontal gas streams during the two kinds of gas blowing processes.

What should again be mentioned is the influence of the buoyancy. With enhancing the backward contracting attacking force and the thrust force stood by the bubbles, it can also alter the motion direction of the bubbles, thus making the backward attacking points involve a larger area of the side wall over the tuyere outlet. This is a special feature of the back-attack phenomenon of a horizontal gas stream. ${ }^{15}$ The downward impinging force of the jet can decrease the effect of the upward buoyancy, so, the increased amplitude of the back-attack intensity resulted from the buoyancy in a combined blowing is lower than that in a simple side blowing. This is another difference between the back-attack phenomena of the horizontal gas streams in the two gas blowing processes. In addition, the obtained influence patterns of the related factors on the back-attack are also relevant to 
their effects on the gas stirring and fluid flow and mixing characteristics in the bath during the blowing process given in Refs. 17) and 18).

\subsection{Eroded and Worn Rate of Refractory Lining in Combined Side and Top Blowing AOD Refining Process}

The average eroded and worn rates of the boric acid plates after the gas blowing treatment of $30 \mathrm{~min}$ by the AOD water modeling at the given operating modes are given in Fig. 9. The mass loss of the plate during the treatment included not only the contributions of the back-attack and the mechanical erosion of the motioning liquid and other actions, but also the dissolution loss of the boric acid in the water. The cast-plates used for the experiments were all very dense; their dissolution losses were not large, being 10 to $16 \%$ of the total mass loss amounts under the conditions of this work. Therefore, it may be considered that the erosion and wear of the plate is mainly resulted from the back-attacking and the erosion of the liquid. The mass loss of the plate with its appearance and morphology after the treatment would be able to fully reflect the action and influence of the back-attack on the erosion and wear of the lining.

As shown in Fig. 9, the eroded and worn average rates during the simple side and combined blowing at the given operating modes were in the ranges of 0.592 to $0.920 \mathrm{~g} / \mathrm{min}$ and 0.570 to $0.823 \mathrm{~g} / \mathrm{min}$, respectively, larger than those in the preliminary investigation. ${ }^{16)}$ In view of a still higher kinematic similarity between the model and its prototype in this work, the results obtained would be able to better characterize the situations of the real refining process. Relative to those during the treatment of $10 \mathrm{~min}$ by the water modeling of the refining process in an $18 \mathrm{t}$ AOD vessel, ${ }^{15}$ ) the average rates decreased approximately by 49 to $67 \%$ for the simple side blowing, and about by 54 to $68 \%$ for the combined blowing. Although it is not so suitable to directly compare to the both each other, a qualitative concept can still be given. The discrepancy of the average rates for the both would be related to the relevant back-attack phenom-

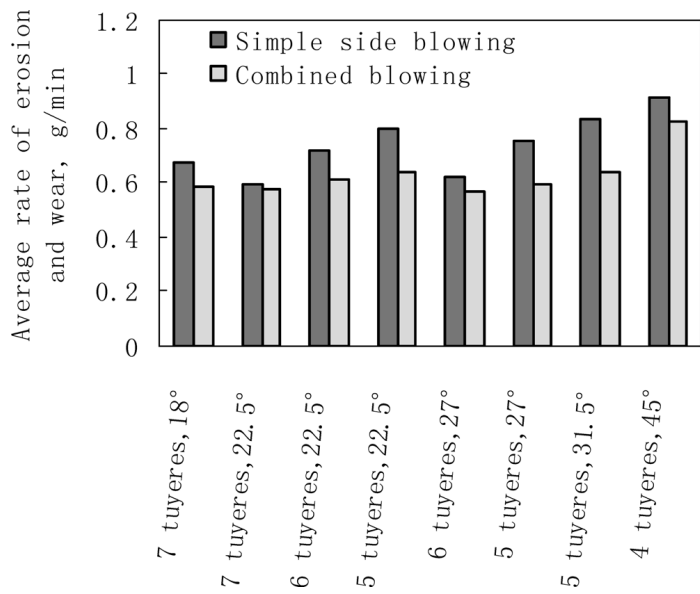

Fig. 9. Eroded and worn average rates of boric acid plates during water modeling of the AOD processes with simple side as well as combined side and top blowing at the given operating modes (gas blowing rates of the top lance, main tuyeres and subtuyeres: $79.87,92.16$ and $9.62 \mathrm{Nm}^{3} / \mathrm{h}$, treatment time: $30 \mathrm{~min}$ ). ena and the influences of the buoyancy on them at the different capacities and tuyere numbers and blowing operations.

The eroded and worn average rates of the plates reached at the given blowing conditions are corresponding to the back-attacking described above. It can be seen from Fig. 9 that at a given gas side blowing rate and angle between each tuyere, the rate in the case of simple side blowing increased with a decrease in the tuyere number. At an angle of $22.5^{\circ}$, the rates with 6 and 5 tuyeres were larger than that with 7 tuyeres by about $22 \%$ and $35.6 \%$, respectively. At an angle of $27^{\circ}$, the rate with 5 tuyeres was higher about by $21.4 \%$ than that with 6 tuyeres. This is entirely in agreement with the influencing patterns of the tuyere number and gas flow rate for single tuyere on the back-attack behaviors. At a given gas side blowing rate and tuyere position, a decrease in the tuyere number can accelerate the lining erosion and wear due to intensifying the back-attack. In addition, it seems that there was not an obvious pattern for the influence of the tuyere position on the rate at a given gas side blowing rate and tuyere number. However, the rate decreased to some extent with increasing of the angle between each tuyere in the range of $18^{\circ}$ to $27^{\circ}$. The rates with $31.5^{\circ}$ ( 5 tuyeres) and $45^{\circ}$ ( 4 tuyeres) were all larger. This is also roughly relevant to the changing pattern of the back-attack behaviors with the variation of the angle. At a certain tuyere number, a suitable increase in the angle is advantageous to alleviating the back-attacking, thus also to slowing down the erosion and wear of the lining.

During the combined blowing, the eroded and worn average rate of the plate also increased with reducing of the tuyere number. The influencing pattern of the tuyere position on it was also not so evident. However, Fig. 9 clearly illustrated that at a given tuyere number and position and gas side blowing rate, the rates in the combined blowing all were lower than those in the simple side blowing. Under the conditions of this work, compared to those in the simple side blowing, the rates in the combined blowing lowered about by 8.4 to $23 \%$, the smallest being still by $2.2 \%$ or so (for 7 tuyeres with $22.5^{\circ}$ ). Such a tendency was also found in the preliminary investigation. ${ }^{16)}$ As mentioned above, in the case of combined blowing, the forces acted on the pressure sensor and measured by it not necessarily all point to the side wall; and the increased amplitude of the back-attack intensity caused by the buoyancy is lower than that in a simple side blowing. The actual attacking force suffered by the side wall would be smaller than that in a simple side blowing. This kind of the influence of the jet on the erosion and wear of the lining obtained experimentally also agrees with the fact of the AOD lining life with combined blowing being longer than that with simple side blowing.

Comparatively, the rates for both the simple side and combined blowing were all in a smallest range when using 7 tuyeres with $22.5^{\circ}$ and 6 tuyeres with $27^{\circ}$. Those were the largest at 4 tuyeres with $45^{\circ}$, which would directly be interrelated with an increase in the gas blowing rate for single tuyere. These are also completely in accordance with the influence of the tuyere equipment and arrangement on the back-attacking. 


\subsection{Morphologies and Appearances of Erosion and Wear of Refractory Lining in Combined Side and Top Blowing AOD Refining Process}

The morphologies and appearances of the plates after the gas blowing treatment by the AOD water modeling of simple side and combined blowing at the given operating modes are presented in Figs. 10 and 11, respectively. After the gas blowing treatment of $30 \mathrm{~min}$, the plates were remarkably changed into thinner, especially at the periphery area close to the tuyere outlets. It can be seen from the two figures that the plates at and near the tuyere outlets were excessively and non-uniformly eroded and worn due to the back-attacking. A series of clearly discernible dented pits and pocked marks were taken shape in a quite large zone near and over the tuyere outlets. The nearer the position from the tuyere outlets, the more and deeper the pits and marks became. Obviously, the erosion of the liquid in motion and the dissolution of the boric acid would make the plates more uniformly and wholly change into thinner. The pits and marks would be resulted from striking and eroding repeatedly by a group of the bubbles during the back-attacking.

At the tuyere equipments and arrangements taken in this work, the damaged areas of the plates in the combined blowing, generally, were smaller than those in the simple side blowing. This is also related to the different influences of the buoyancy on the back-attack behaviors in the two blowing processes.

When taking 7 tuyeres with $22.5^{\circ}$ and 6 tuyeres with $27^{\circ}$, the damaged extents of the plates in both the simple side and combined blowing at the given gas flow rates, relatively, were all gentler than those with the other schemes. Appropriately, the dent pits and pock marks formed were fewer, shallower and evener, and their distribution area was smaller. These kinds of morphology and appearance features with the damaged states of the treated plates have entirely been corresponding to the back-attack behaviors and features under the conditions of the combined blowing. Also, those have reflected on the whole the damaged situation of the lining in the practical AOD refining process.

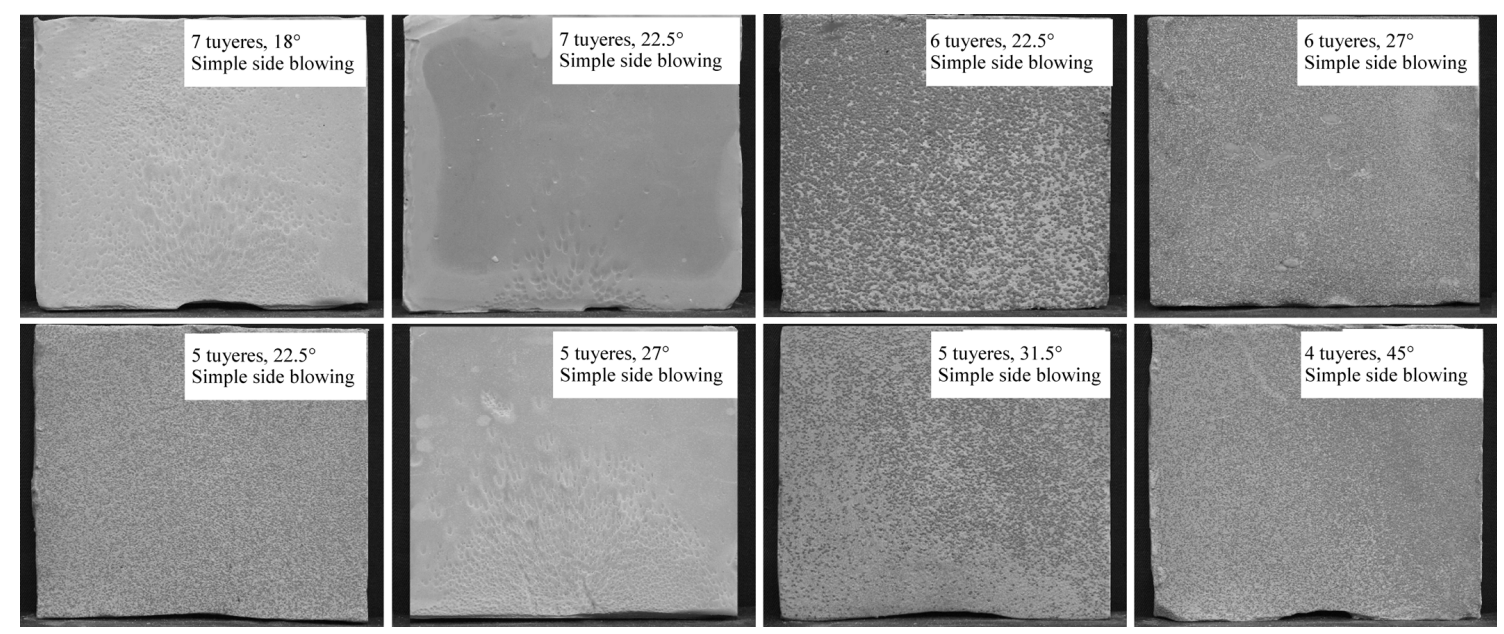

Fig. 10. Morphologies and appearances of boric acid plates after gas blowing treatment by the AOD water modeling of simple side blowing at the given operating modes (gas blowing rates of the main tuyeres and subtuyeres: 92.16 and $9.62 \mathrm{Nm}^{3} / \mathrm{h}$, treatment time: $30 \mathrm{~min}$ ).
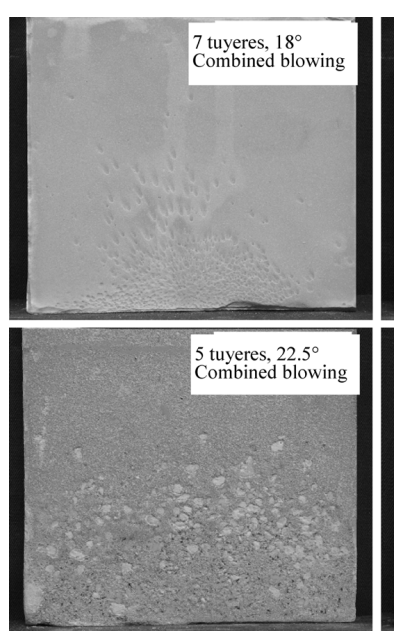
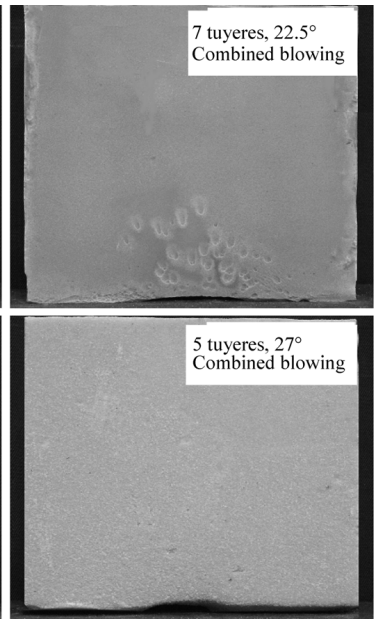
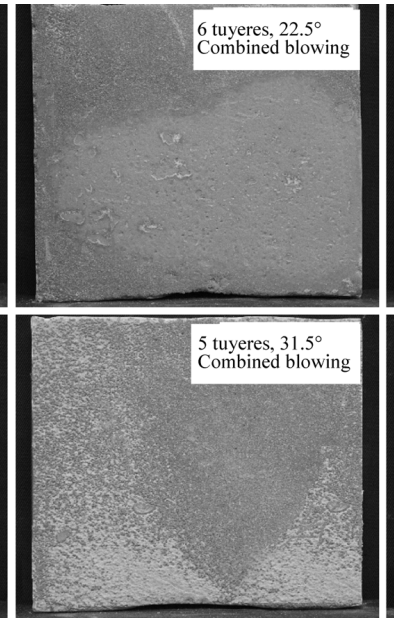

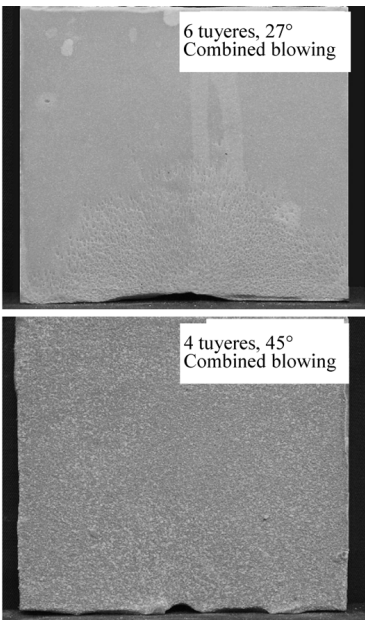

Fig. 11. Morphologies and appearances of boric acid plates after gas blowing treatment by the AOD water modeling of combined side and top blowing at the given operating modes (gas blowing rates of the top lance, main tuyeres and subtuyeres: $79.87,92.16$ and $9.62 \mathrm{Nm}^{3} / \mathrm{h}$, treatment time: $30 \mathrm{~min}$ ). 


\subsection{Preliminary Application of Physical Modeling Re- sults to Industrial Practice}

The tuyere equipment with its arrangement is a key of the shell design of the AOD converter. Its reasonability, to a great extent, is concerned to the efficiency and effectiveness of the refining process. The results of a whole series of the investigations by Wei et al. ${ }^{15-23)}$ with the present work amply showed that the tuyere number and position considerably affect the fluid flow and mixing in an AOD bath, and the stability of the refining process, the lining life and others, thus directly influencing the technical and economic indications of the process. At a given gas side blowing rate, using too many or few tuyeres and an excessively large or small angle between each tuyere will all increase the energy consumption and reduce the effective agitation power input by the gas streams due to the stronger interactions among them. Those will make the mixing efficiency decrease, the refining reactions be uneasy to proceed successfully and fully, and the lining life shorten, and so on. For an AOD converter with a given capacity, there would be an optimal equipment and arrangement scheme of the tuyere. With the scheme, the bath would be both active and stable; the highest mixing efficiency and refining rate, the best refining result and the longest lining life would be able to be provided. For a long time past, people have all primarily been considering the equipment and arrangement from the data given by Leach et al. ${ }^{24)}$ Actually, they did not achieve a sufficiently high kinematic similarity between the model and its prototype. ${ }^{21)}$ Hence, their result is not necessarily so exact and reliable, and there would still be a considerable room for improvement. A definite fact is that people have not been attaching sufficient importance to this matter.

The $120 \mathrm{t}$ AOD converter under consideration is equipped with 7 tuyeres, and the angle between each tuyere is $18^{\circ}$. As a matter of fact, it was only an attempt to take this scheme at that time. The results of the physical modeling of the process in this converter ${ }^{16-20,23)}$ including this work illustrated that this scheme would not be so suitable, being difficult to offer the good stirring and mixing in the bath, and the erosion and wear of the lining being more serious.

Based on the results of the physical modeling and comprehensively taken the factors and realities of all the aspects into account, a new scheme of the tuyere equipment and arrangement for the $120 \mathrm{t}$ AOD converter was fixed. According to the scheme, 7 tuyeres were still utilized, but the angle was properly enlarged. A new shell was manufactured in terms of the scheme, and the industrial experiments were conducted with it. In order to test the reliability and believability of the results obtained from the physical modeling and to examine the effectiveness of the scheme in the greatest degree, all the other conditions were maintained to be the original states, without making any change.

Three experimental campaigns were carried out. Compared to a mean value of about 85 heats when using 7 tuyeres with $18^{\circ}$, the lining life was raised by $29.4 \%$ for the first campaign, come to 110 heats. For the second and the third, it was increased by $52.9 \%$ and $42.4 \%$, approached 130 and 121 heats, respectively.

A rise in the lining life can essentially be merely referred to an increase in the angular separation. On the other hand, prolonging of the life would definitely be able to improve the other technical and economical indications. For the three experimental campaigns, the recovery ratios of chromium and nickel, the oxygen supply time (amount), the refining time, the argon consumption, the decarburization rate, the working time of the vessel, the consumption of refractory material and the production cost and other indications were all superior to those when using 7 tuyeres with $18^{\circ}$. This means that the new scheme with a larger angle between each tuyere, to a considerable extent, can heighten the gas stirring efficiency and improve the fluid flow pattern in the bath. Relevantly, it can shorten the mixing time and raise the homogeneities of the temperature and composition in the bath and others. All of these are completely agreement to the conclusions drawn from a whole series of the physical modeling studies.

The remnant thicknesses of the lining at the locations were inspected. For the first campaign, only the residual thicknesses at the side of the tuyere outlets and the zone over the outlets were smaller, being 40 and $50 \mathrm{~mm}$ (approximately $4 \%$ of the lengths of the fresh bricks), respectively. At the other places, including the side opposite the tuyere outlets and the slag line regions of the two trunnions on the left and right sides of the tuyeres, the thicknesses were all large. Thus, the remnant thickness situations of the lining at the locations were favorable except the tuyere outlet side and the zone over the outlets, the uniformity of its erosion and wear became better. According to the previous experience, this vessel can still continue to be used about 20-30 heats.

Due to the limits from some concrete situations and conditions, the new scheme taken are not optimal, and the industrial experiments performed also are only preliminary. However, the results stated that the experiments are very successful, not only having technically a breakthrough and advance to some extent, but also gaining the fairly good economic benefits. The experiments also fully confirmed that the conclusions drawn from a series of physical modeling studies on the combined blowing AOD refining process are reliable, believable and valid. Those can be extended to the industrial practice. In view of this, all the original shells have been fallen into disuse, no longer in use.

In one more year after that, the further industrial experiments with the new shell have continuously been carried out. Some measures, including improving the tuyere design according to the previous studies, ${ }^{25-27)}$ have been taken. The lining life has constantly risen. Recently, it has approached a level of about 200 heats, the highest being 209 heats.

\section{Conclusions}

The back-attack phenomenon of the horizontal gas streams and its influence on the erosion and wear of the lining during the combined side and top blowing process of stainless steel in a $120 \mathrm{t}$ AOD converter have been investigated using water modeling. The preliminary industrial experiments were conducted. The results demonstrated that,

(1) The presence of a gas jet from the top lance and using of multiple tuyere do not change the basic features of the back-attack, but can give it some distinctive behaviors.

(2) The back-attack can indeed bring about the evident 
and uneven erosion and wear of the lining.

(3) On the back-attack, the gas streams of the main tuyeres possess a decisive role, and the subtuyere streams give a certain suppression and alleviation effect.

(4) At a given tuyere number and position, the frequency and pressure and total average pulse number in per unit time of the back-attack in the process increase with an increase in the gas side blowing rate.

(5) At a given tuyere position and gas side blowing rate, the back-attack and its influence on the erosion and wear of the lining enhance with a decrease in the tuyere number (increasing of the gas flow rate for single tuyere).

(6) The gas top blowing jet can make the back-attack become more uniform and its frequency reduce, and its intensity and the total average pulse number in per unit time increase; and it can reduce the eroded and worn rate of the lining at a given tuyere number and position and gas side blowing rate.

(7) The increased amplitude of the back-attack intensity and the extension of the damaged area of the lining caused by the buoyancy in a combined blowing are smaller and lower than those in a simple side blowing.

(8) As another important reason resulted in the back-attack and the erosion and wear of the lining, the effectiveness of the circulatory motion of the liquid in a combined blowing is different from that in a simple side blowing.

(9) At a given tuyere number, properly increasing the angle between each tuyere is advantageous to alleviating the back-attack and to slowing down the erosion and wear of the lining.

(10) Under the conditions of this work, the back-attack actions and the eroded and worn extents and rates of the lining with 7 tuyeres and $22.5^{\circ}$ or 6 tuyeres and $27^{\circ}$ are all gentler and lower than those with the other tuyere equipments and arrangements.

(11) The results obtained from the physical modeling studies on the refining process are reliable, believable and valid. Suitably increasing the angle between each tuyere of the $120 \mathrm{t}$ AOD converter can raise the life of its lining by a big margin, and remarkably improve the technical and economic indications of the process.

\section{Acknowledgement}

The authors gratefully acknowledge the combined support of The National Natural Science Foundation of China and Shanghai Baoshan Iron \& Steel Co., Ltd. (Grant No. 50374047).

\section{REFERENCES}

1) L. Farias and D. G. C. Robertson: Injection Phenomena in Extraction and Refining, Vol. 1, ed. by A. E. Wraith, University of Newcastle upon Tyne, England, (1982), E1.

2) K. Suzuki, M. Tanaka, K. Nakanishi and J. Matsuno: Trans. Iron Steel Inst. Jpn., 22 (1982), No. 8, B237.

3) Y. Ozawa and K. Mori: Trans. Iron Steel Inst. Jpn., 23 (1983), No. 9, 764.

4) J. K. Brimacombe, S. E. Meredith and R. G. H. Lee: Metall. Trans. $B, 15$ (1984), 243.

5) S. Gustafsson and G. Terner: Proc. Symp. on Injection Metallurgy and Secondary Refining of Steel, CMS, Beijing, China, (1984), R15.

6) Y.-Z. Li, Y.-X. Huang, Y.-P. He and X.-Y. Liu: Symp. on 2nd National Kinetics of Metallurgical Reactions, Vol. II, CMS, Beijing, China, (1984), 335

7) Y. Ozawa and K. Mori: Trans. Iron Steel Inst. Jpn., 26 (1986), No. 4, 291.

8) Y. W. Cho and J. K. Yoon: SCANINJECT IV, Part I, MEFOS, Luleå, Sweden, (1986), No. 4 Article.

9) G. Carlsson and E. Burström: Scand. J. Metall., 15 (1986), 298.

10) T. Aoki, S. Masuda, A. Hatano and M. Taga: Injection Phenomena in Extraction and Refining, Vol. 1, ed. by A. E. Wraith, University of Newcastle upon Tyne, England, (1982), A1.

11) T. Aoki: Tetsu-to-Hagané, 76 (1990), No. 11, 1996.

12) T. Aoki: Tetsu-to-Hagané, 76 (1990), No. 11, 2004.

13) L. Farmer, D. Lach, M. Lanyi and D. Winchester: Proc. Steelmaking Conf., ISS/AIME, USA, 76 (1989), 487.

14) P. Blostein, M. Buffenoir, E. Streicher and J. Mettet: SCANINJECT VI, Part I, MEFOS, Luleå, Sweden, (1992), 129.

15) J.-H. Wei, J.-C. Ma, Y.-Y. Fan, N.-W. Yu, S.-L. Yang and S.-H. Xiang: ISIJ Int., 39 (1999), No. 8, 779.

16) X.-C. Wang: M. D. Thesis, Shanghai University, (2004).

17) J.-H. Wei, H.-L. Zhu, H.-B. Chi and H.-J. Wang: ISIJ Int., 50 (2010), No. $1,17$.

18) J.-H. Wei, H.-L. Zhu, H.-B. Chi and H.-J. Wang: ISIJ Int., 50 (2010), No. $1,26$.

19) H.-L. Zhu: Ph. D. Thesis, Shanghai University, (2006).

20) J.-H. Wei, H.-L. Zhu, S.-L. Yang, X.-C. Wang, J.-C. Ma, G.-M. Shi, Q.-Y. Jiang, H.-B. Chi, L.-B. Che and K. Zhang: Steel Res. Int., 76 (2005), No. 5, 362.

21) J.-H. Wei, J.-C. Ma, Y.-Y. Fan, N.-W. Yu, S.-L. Yang, S.-H. Xiang and D.-P. Zhu: Ironmaking Steelmaking, 26 (1999), No. 5, 363.

22) J.-H. Wei, J.-C. Ma, Y.-Y. Fan, N.-W. Yu, S.-L. Yang, S.-H. Xiang and D.-P. Zhu: Iron Steelmaker, (2001), No. 4, 59.

23) H.-J. Wang: M. D. Thesis, Shanghai University, (2005).

24) J. C. C. Leach, A. Rodgers and G. Sheehan: Ironmaking Steelmaking, 5 (1978), No. 5, 107.

25) J.-H. Wei, S.-H. Xiang, Y.-Y. Fan, N.-W. Yu, J.-C. Ma and S.-L. Yang: Ironmaking Steelmaking, 27 (2000), No. 4, 294.

26) J.-H. Wei, S.-H. Xiang, Y.-Y. Fan, N.-W. Yu, J.-C. Ma and S.-L. Yang: Steel Res., 72 (2001), No. 5-6, 161.

27) J.-H. Wei, S.-H. Xiang, Y.-Y. Fan, N.-W. Yu, J.-C. Ma and S.-L. Yang: Steel Res., 72 (2001), No. 5-6, 168. 